\title{
Numerical Analysis of Aerodynamic Performance Characteristics of NACA 2312 and NACA 2412
}

\author{
Pritam Saha \\ Student of B.Tech Aerospace Engineering \\ Lovely Professional University \\ Jalandhar, India
}

\author{
Harshpreet Singh Kaberwal \\ Student of B.Tech Aerospace Engineering \\ Lovely Professional University \\ Jalandhar, India
}

\begin{abstract}
Comparison of the Aerodynamic Performance characteristics of NACA 2312 and NACA 2412 aerofoils under the same flow conditions at a Reynolds number of $2.74 \times 10^{6}$ is presented. ANSYS is used for the creation of geometry and meshing and FLUENT is used as a solver. Coefficient of lift and coefficient of drag for both aerofoils are compared for a range of Angle of Attack while the free stream velocity of air is kept constant. This analysis can be used for the wing design and other aerodynamic modelling corresponds to these aerofoils
\end{abstract}

Keywords:- Aerofoil, Angle of Attack, Coefficient of lift, Coefficient of drag, K-omega SST, NACA2312, NACA2412.

\section{INTRODUCTION}

In the study of aerodynamics, our main concern is about the forces applied by air molecules on an object's surfaces which results from the air's flow with respect to that object. These forces, along with the moment they generate about an aircraft's centre of gravity, determines its performance and stability during a flight. The sum total of these forces applied by flowing air molecules on an object's surface results in a net force which can be separated into two components which are lift force and drag force. Drag is an aerodynamic force which resists the object's motion against the airflow, while lift is an aerodynamic force which works against the direction of gravity. Objects with every kind of shapes experience a significant magnitude of drag from airflow, but for most shapes the lift generated on the object is negligible unless the flow velocity is high. Aerofoil is a shape which generates a significant magnitude of lift force in an airflow and therefore all heavier than air aircraft's lift generating surfaces have an aerofoil shaped cross-section. From a logical deduction backed up by experimental evidence, we know that as an aerofoil shaped wing's angle of attack changes, the lift and drag force on that wing also changes. And the shape of the wing's crosssection determines the relationship of these aerodynamic forces with respect to the wing's angle of attack and therefore the wing's performance. This means that wings with different aerofoil cross-sections have different aerodynamic performance characteristics.
These aerofoil shapes are described by a coding system devised by the National Advisory Committee for Aeronautics (NACA). The four-digit system define the wing's cross-sectional profile by using a series of four digits following "NACA". In this system the first digit describes maximum camber as percentage of the chord. The second digit describes the distance of maximum camber from the aerofoil's leading edge in tenths of the chord. Last two digits describes maximum thickness of the aerofoil as percent of the chord. It is convenient to name the aerofoils using this system as its precise cross-section can be generated and its properties can be calculated using the digits in the code name.

\section{COMPUTATIONAL METHOD}

In this paper NACA 2312 and NACA 2412 aerofoils were utilized. The NACA 2312 is a cambered aerofoil; 2 indicates that it's maximum camber is equal to two percent of its chord length and 3 indicates that it's maximum camber is located at a distance from the leading edge which is equal to the thirtieth part of its chord length. 12 indicates that the aerofoil has a $12 \%$ thickness to chord length ratio. Reynolds number for the simulation was $R e=2.74 \times 10^{6}$. The density of air at given temperature is $\rho=$ $1.225 \mathrm{~kg} / \mathrm{m}^{3}$ and the viscosity is $\mu=1.7894 \times$ $10^{-5} \mathrm{~kg} /(m * s)$. The turbulent viscosity is computed through K-omega SST model.

\section{DOMAIN GENERATION}

The computational domain has a geometry as shown in the figure below. The semi-circular section has a radius of $12.5 \mathrm{~m}$ while the rectangular section has a length of $20 \mathrm{~m}$. The aerofoil which has a chord length of $1 \mathrm{~m}$ is placed in the domain such that its trailing edge is at the centre of the diameter of semi-circular region of the domain and its chord-line coincides with the line of symmetry of the domain. The velocity inlet boundary condition was applied for in flow with a speed of $40 \mathrm{~m} / \mathrm{s}$. Similarly, outlet boundary condition was applied for the outflow. Wall condition was applied for other boundaries. The cosine component of the flow velocity is parallel to the $\mathrm{x}$-axis while the sine component of this flow velocity is parallel to the y-axis of the domain. For this study it is assumed that the turbulence of inflow is very less as compared to the outflow and therefore the turbulence intensity for the velocity inlet boundary condition is considered to be $0.1 \%$. 


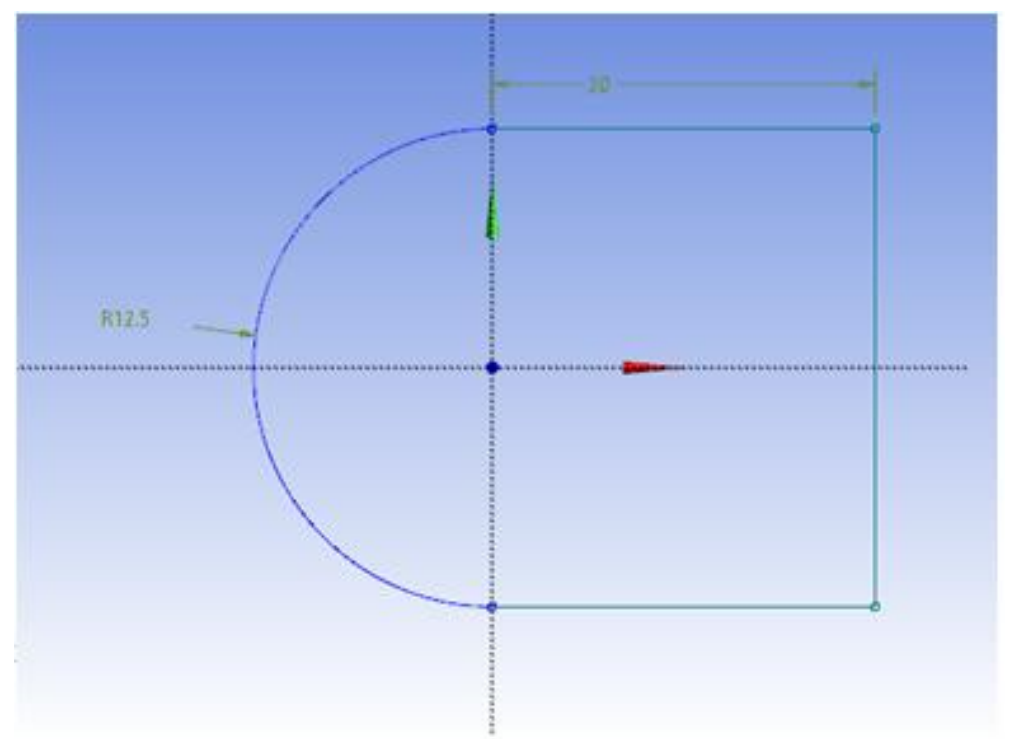

Fig 1:- The dimensions and boundary conditions of the computational domain

\section{MESHING}

The aerofoil coordinates were obtained from the aerofoil database and imported onto design modeller of ANSYS. The domain was created and split into different domains for meshing. The model is as shown in the figure. Both the aerofoils had the same domain dimensions.

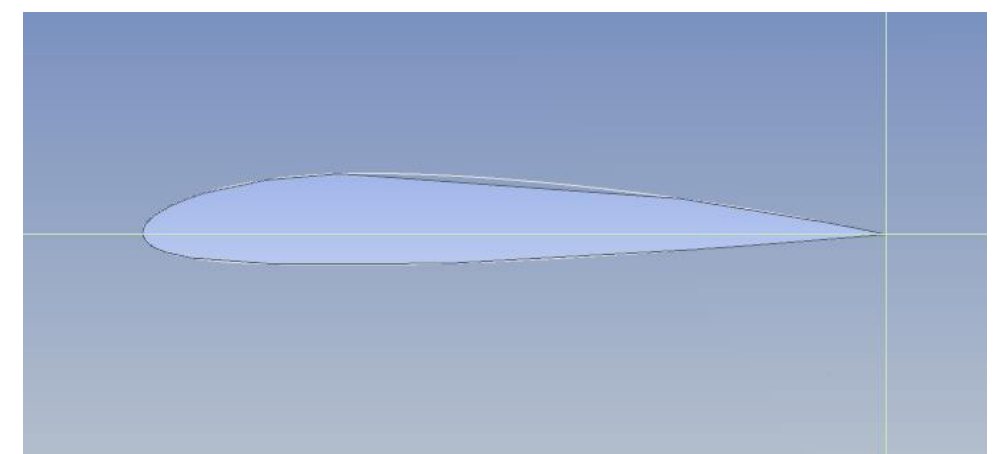

Fig 2:- Geometry of NACA 2312 created in Design modeller

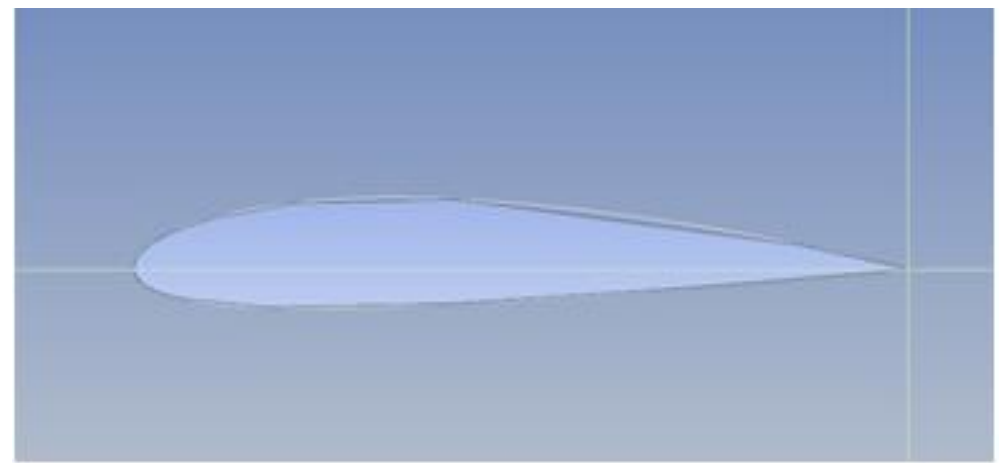

Fig 3:- Geometry of NACA 2412 created in Design modeller

The meshes were generated using Meshing component of ANSYS. A C grid structured mesh was generated and the figure is as shown below: 


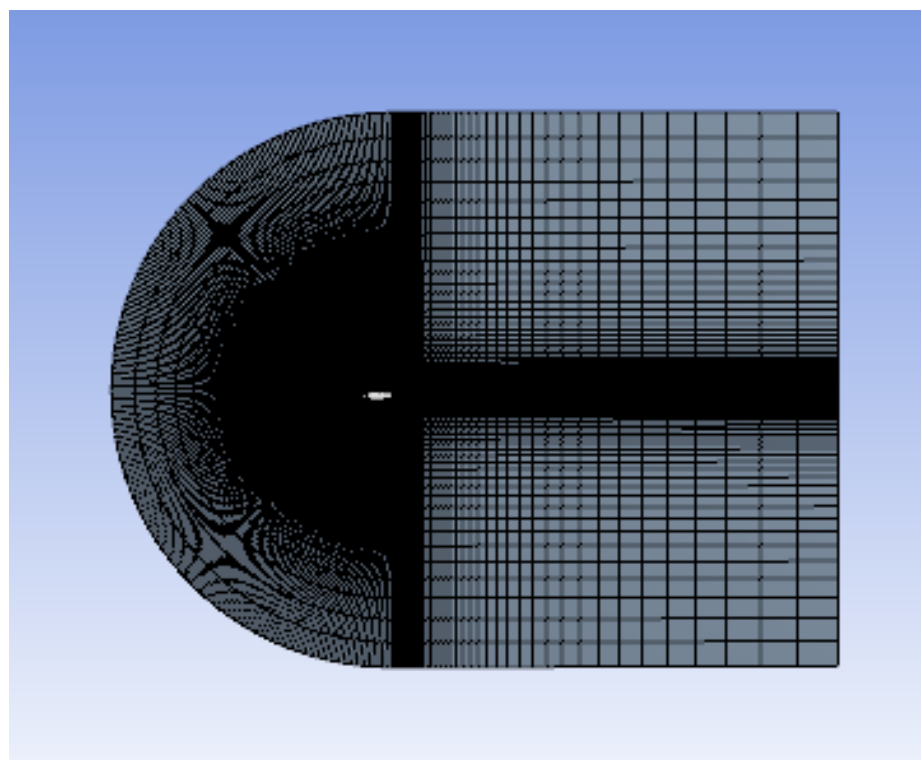

Fig 4:- Mesh of NACA 2312

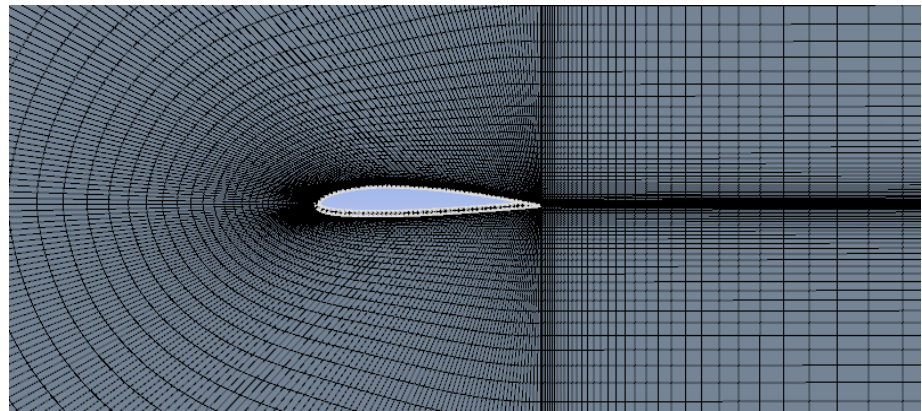

Fig 5:- Closeup of the Mesh of NACA 2312

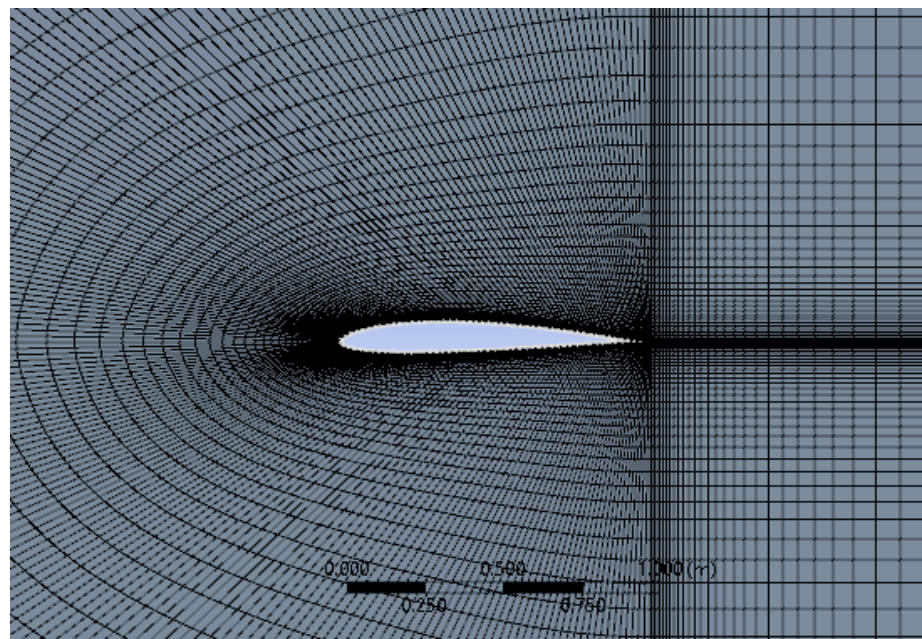

Fig 6:- Closeup of the Mesh of NACA 2412

The mesh quality was found to be optimal. The meshes were imported into the fluent solver where the boundary conditions, turbulence model etc were selected.

\section{PROCESSING ON FLUENT AND SELECTION OF TURBULENCE MODEL}

Turbulence model is the construction with the help of mathematical models to predict the effects of turbulence on the aerofoil.
$\mathrm{K}-\omega$ model is a two-equation turbulence model which is used for RANS equations. It uses two variables, $\mathrm{k}$ which is the kinetic energy and $\omega$ which is the specific rate of dissipation. This model is combined with SST model which is Shear Stress Transport which is also widely used.

The input parameters along with specific conditions as indicated in the table below were given on FLUENT. 
ISSN No:-2456-2165

\begin{tabular}{|c|c|}
\hline Solver & Pressure based steady \\
\hline Viscous Model & K- $\omega$ SST model \\
\hline Density(kg/m3) & 1.225 \\
\hline Viscosity(kg/m-s) & $1.7894 \mathrm{e}-05$ \\
\hline Turbulence intensity ratio & 0.1 \\
\hline Turbulence length scale & 0.3 \\
\hline Inlet Velocity(m/s) & 40 \\
\hline Reynolds Number & $2.74 \times 10^{\wedge} 6$ \\
\hline Chord length(m) & 1 \\
\hline Momentum & Second Order Upwind \\
\hline Pressure velocity coupling & Coupled \\
\hline
\end{tabular}

Table 1:- Fluent details

\section{RESULT}

\section{A. Pressure Contours}

The Pressure contours for 2312 and 2412 at various angle of attacks are shown below.

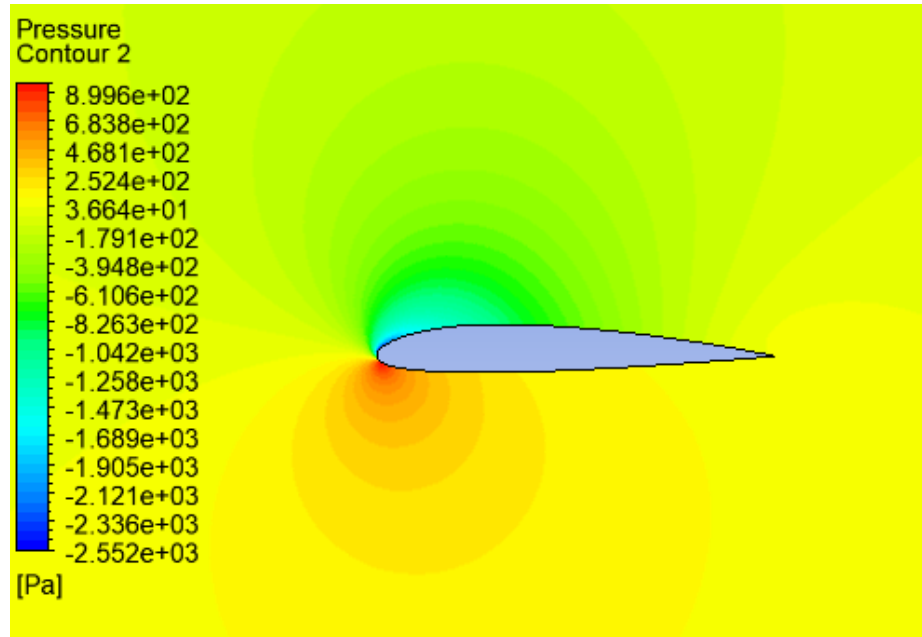

Fig 7:- Pressure contour for NACA 2312 at $8^{\circ}$ angle of attack

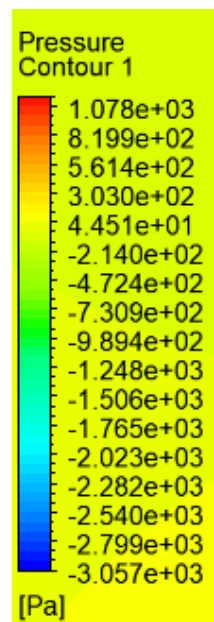

Fig 8:- Pressure contour for NACA 2412 at $8^{\circ}$ angle of attack. 


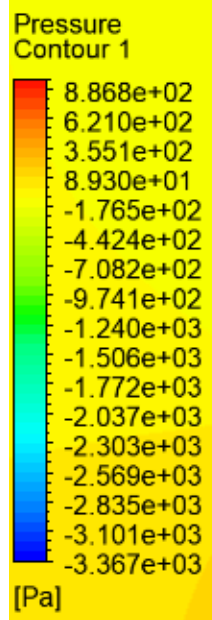

Fig 9:- Pressure contour for NACA 2312 at $10^{\circ}$ angle of attack.

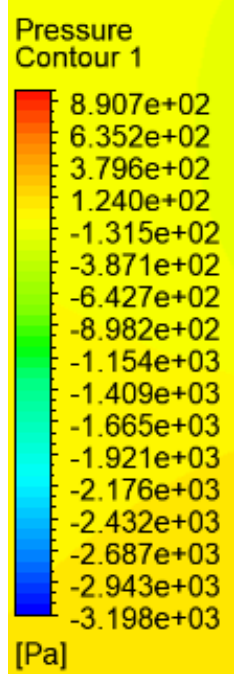

Fig 10:- Pressure contour for NACA 2412 at $10^{\circ}$ angle of attack.

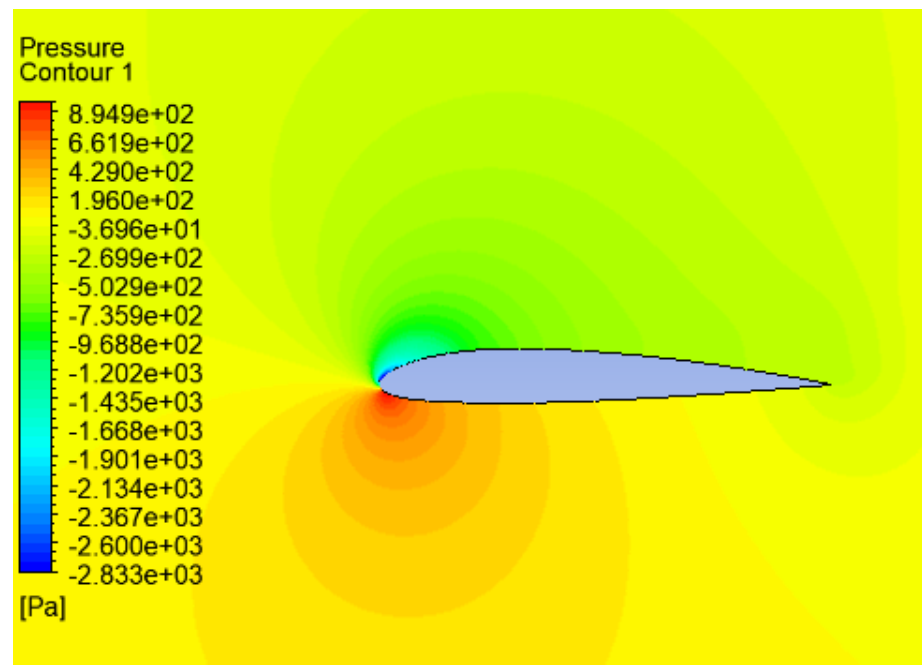

Fig 11:- Pressure contour for NACA 2312 at $12^{\circ}$ angle of attack. 


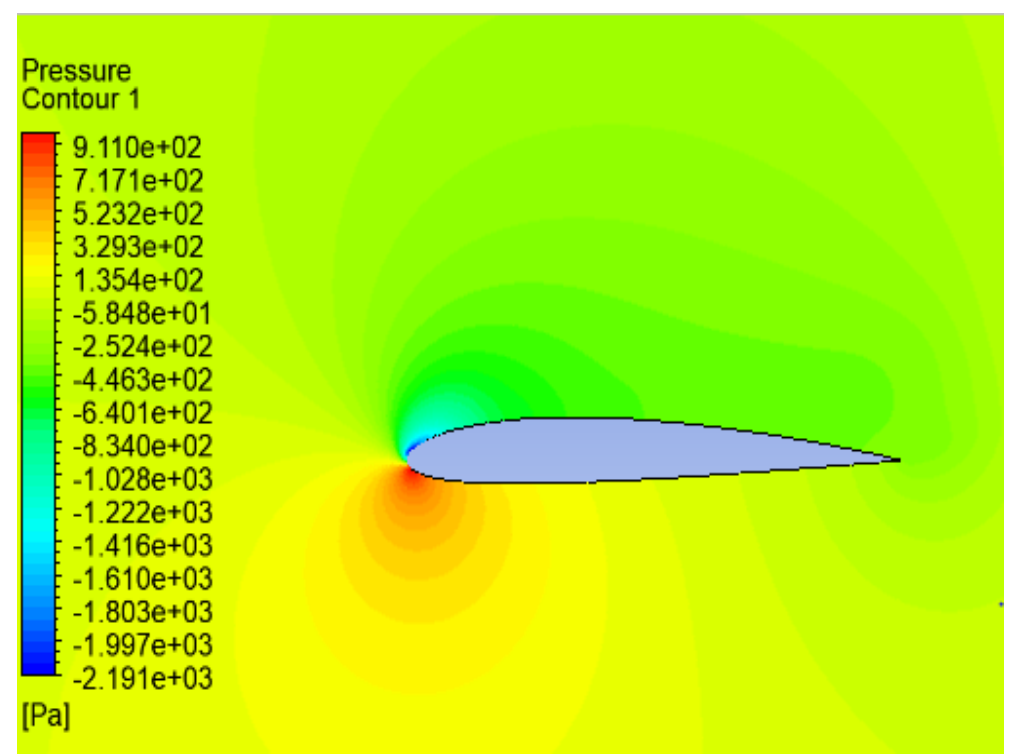

Fig 12:- Pressure contour for NACA 2412 at $12^{\circ}$ angle of attack.

\section{B. Velocity Contours}

The Velocity contours for 2312 and 2412 at various angle of attacks are shown below.

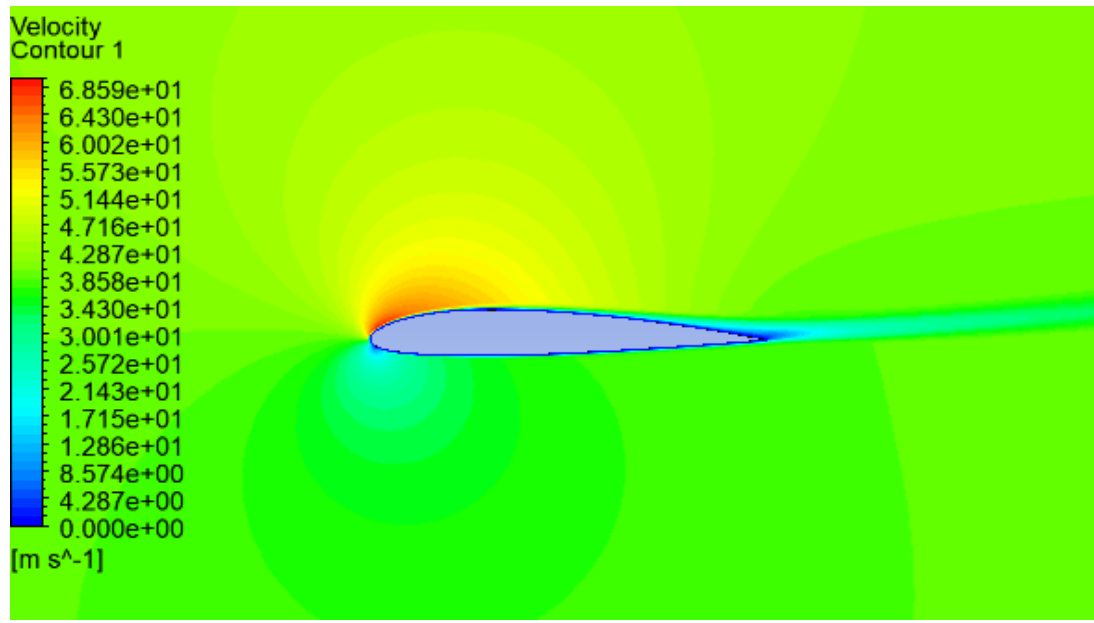

Fig 13:- Velocity contour for NACA 2312 at $8^{\circ}$ angle of attack.

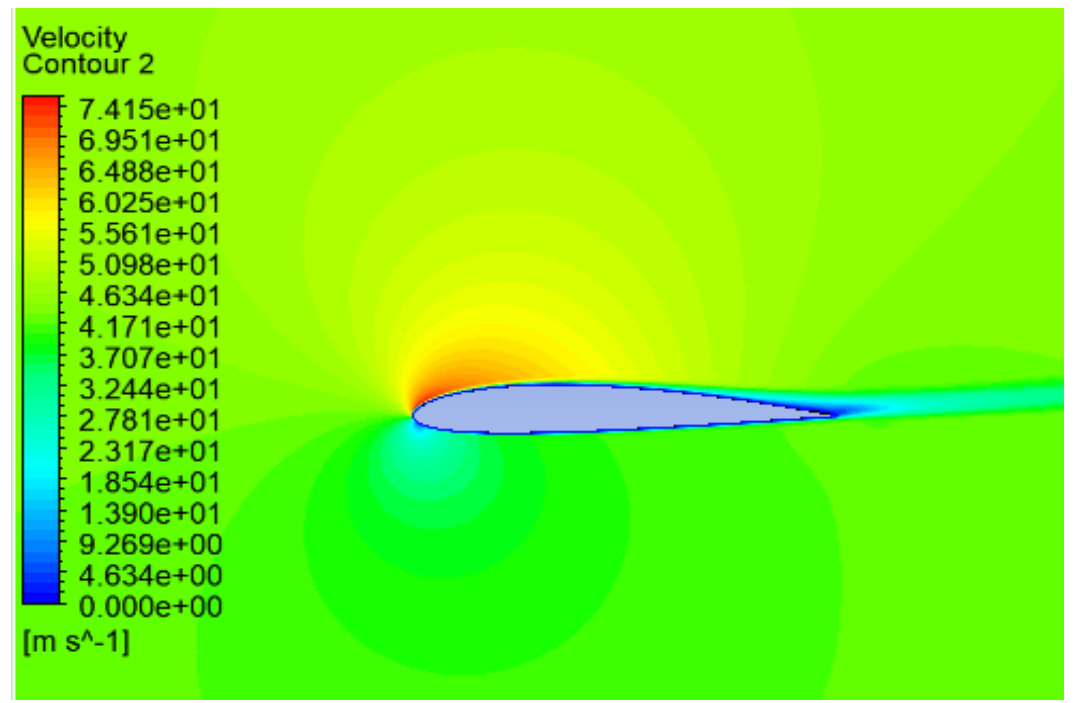

Fig 14:- Velocity contour for NACA 2412 at $8^{\circ}$ angle of attack. 


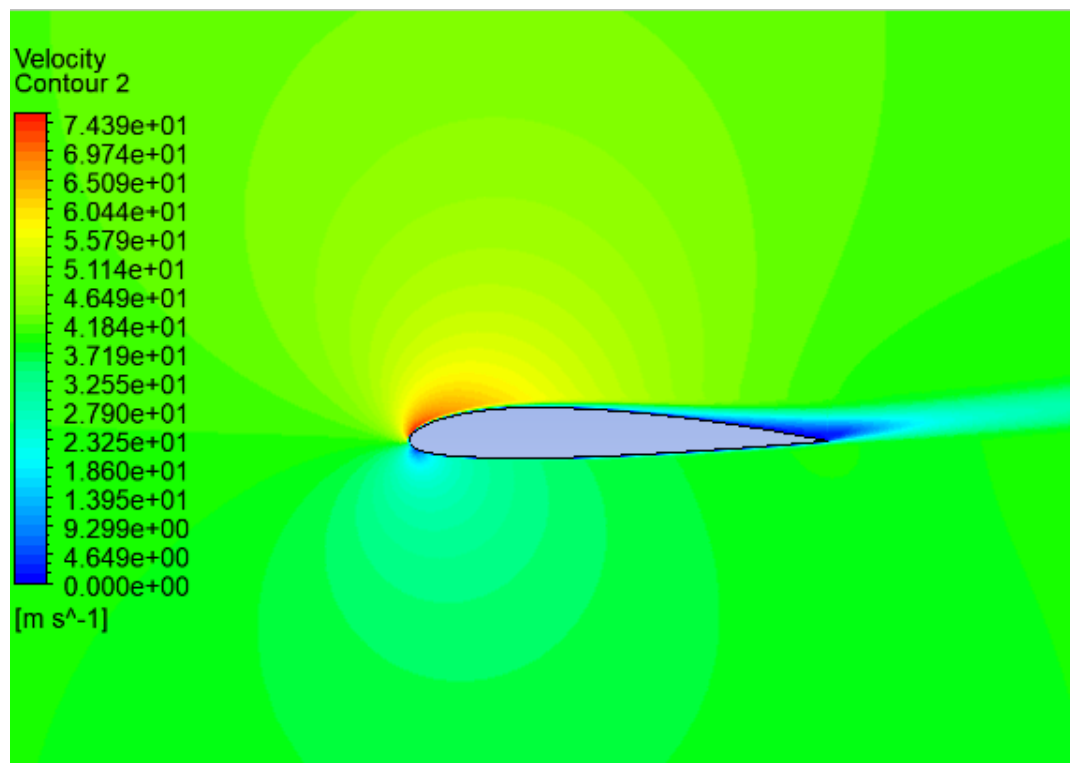

Fig 15:- Velocity contour for NACA 2312 at $10^{\circ}$ angle of attack.

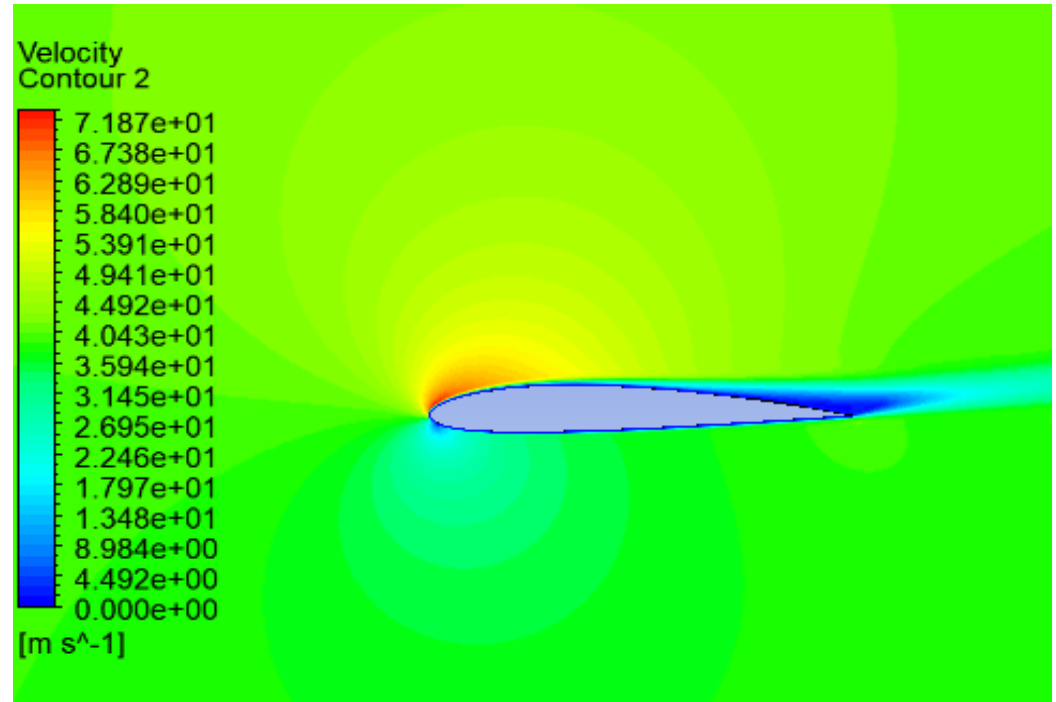

Fig 16:- Velocity contour for NACA 2412 at $10^{\circ}$ angle of attack.

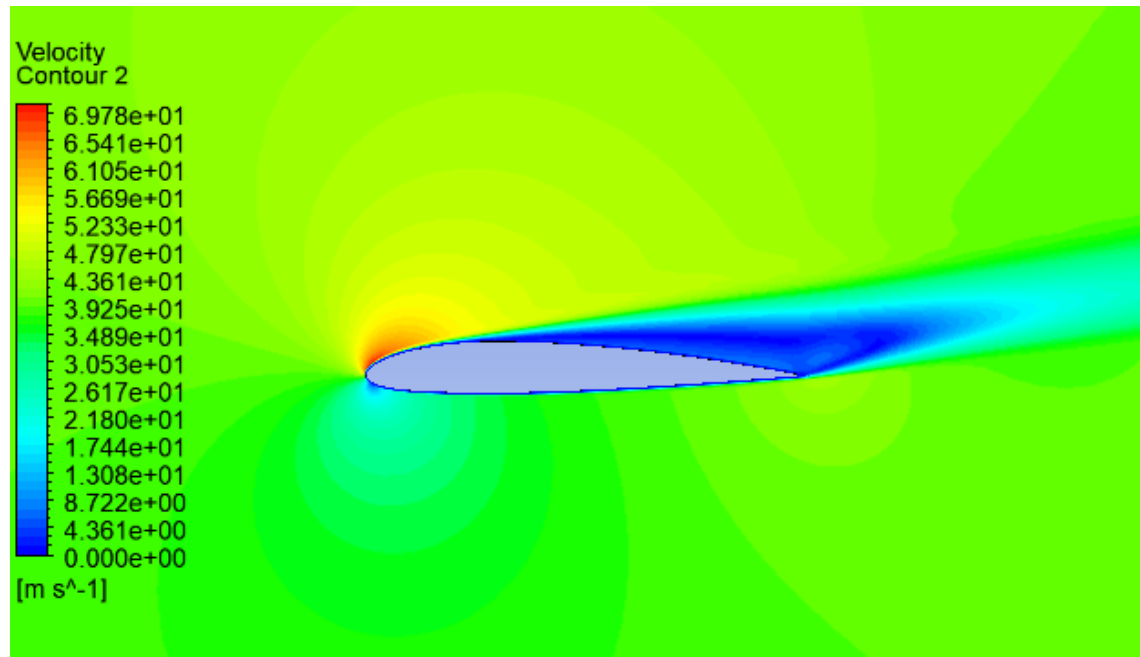

Fig 17:- Velocity contour for NACA 2312 at $12^{\circ}$ angle of attack. 


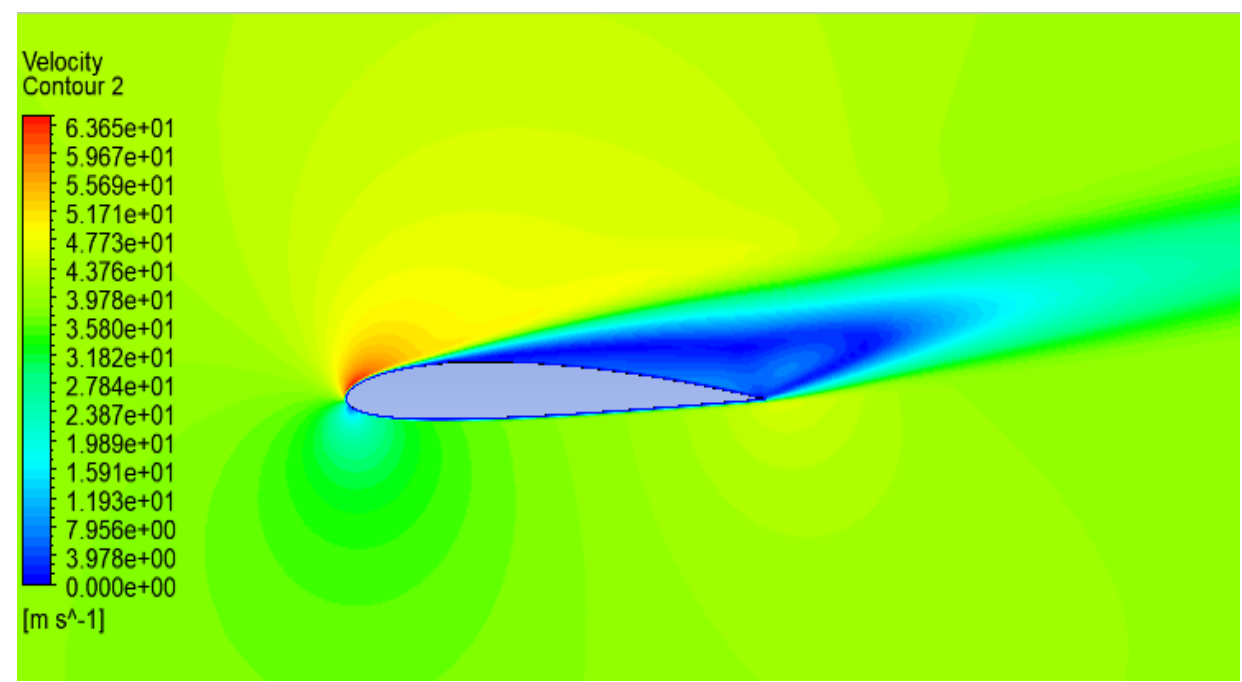

Fig 18:- Velocity contour for NACA 2412 at $12^{\circ}$ angle of attack.

C. Comparison Plots of Aerodynamic Force Coefficients

The plots of Coefficient of Lift $(\mathrm{Cl})$ vs Angle of Attack $(\alpha)$ and Coefficient of Drag (Cd) vs. Angle of Attack $(\alpha)$ for both the aerofoils are given below. The variation of coefficients of lift and drag with respect to Angle of Attack can be observed. The Angle of Attack at which the maximum value of Coefficient of $\mathrm{Lift}\left(\mathrm{Cl}_{\max }\right)$ is obtained for a given aerofoil is the stall angle for that aerofoil.

\begin{tabular}{|c|c|c|}
\hline Angle of Attack ( ${ }^{\circ}$ & $\begin{array}{c}\text { Coefficient of Lift } \\
\text { NACA 2312 }\end{array}$ & $\begin{array}{c}\text { Coefficient of Lift } \\
\text { NACA 2412 }\end{array}$ \\
\hline-2 & -0.011472707 & 0.001348805 \\
\hline 0 & 0.19518442 & 0.2051053 \\
\hline 2 & 0.40194063 & 0.40897797 \\
\hline 4 & 0.60587971 & 0.60687999 \\
\hline 6 & 0.79567216 & 0.78987612 \\
\hline 8 & 0.96183318 & 0.91526488 \\
\hline 11 & 1.0685314 & 1.0117007 \\
\hline 12 & 1.0596698 & 0.93399856 \\
\hline
\end{tabular}

Table 2:- Coefficient of Lift of NACA 2312 and NACA 2412 aerofoils at different Angles of Attack

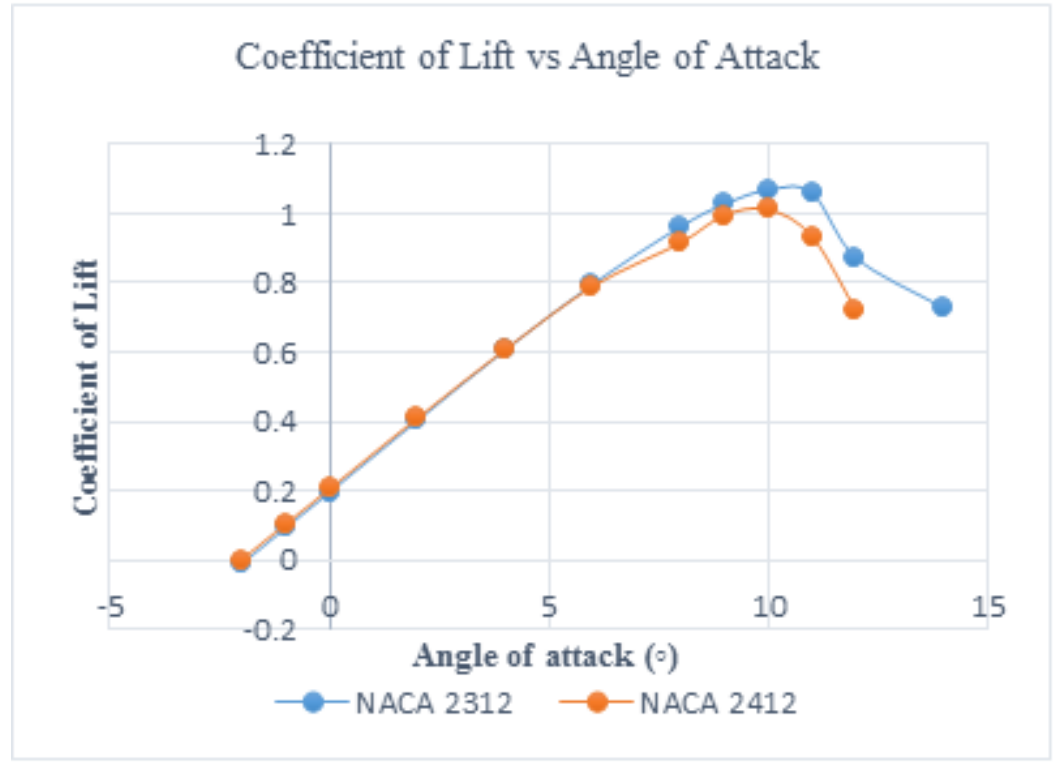

Fig 19:- Coefficient of lift vs Angle of attack 
ISSN No:-2456-2165

\begin{tabular}{|c|c|c|}
\hline Angle of Attack ( ${ }^{\circ}$ ) & $\begin{array}{c}\text { Coefficient of Drag } \\
\text { NACA 2312 }\end{array}$ & $\begin{array}{c}\text { Coefficient of Drag } \\
\text { NACA 2412 }\end{array}$ \\
\hline-2 & 0.01333795 & 0.013932296 \\
\hline 0 & 0.012839723 & 0.013197906 \\
\hline 2 & 0.013318323 & 0.013935515 \\
\hline 4 & 0.015256597 & 0.016163741 \\
\hline 6 & 0.018795264 & 0.020385521 \\
\hline 8 & 0.0247867 & 0.027759399 \\
\hline 10 & 0.035925133 & 0.042929056 \\
\hline 11 & 0.047646486 & 0.063855029 \\
\hline 12 & 0.086064073 & 0.10162754 \\
\hline
\end{tabular}

Table 3:- Coefficient of Drag of NACA 2312 and NACA 2412 aerofoils at different Angles of Attack

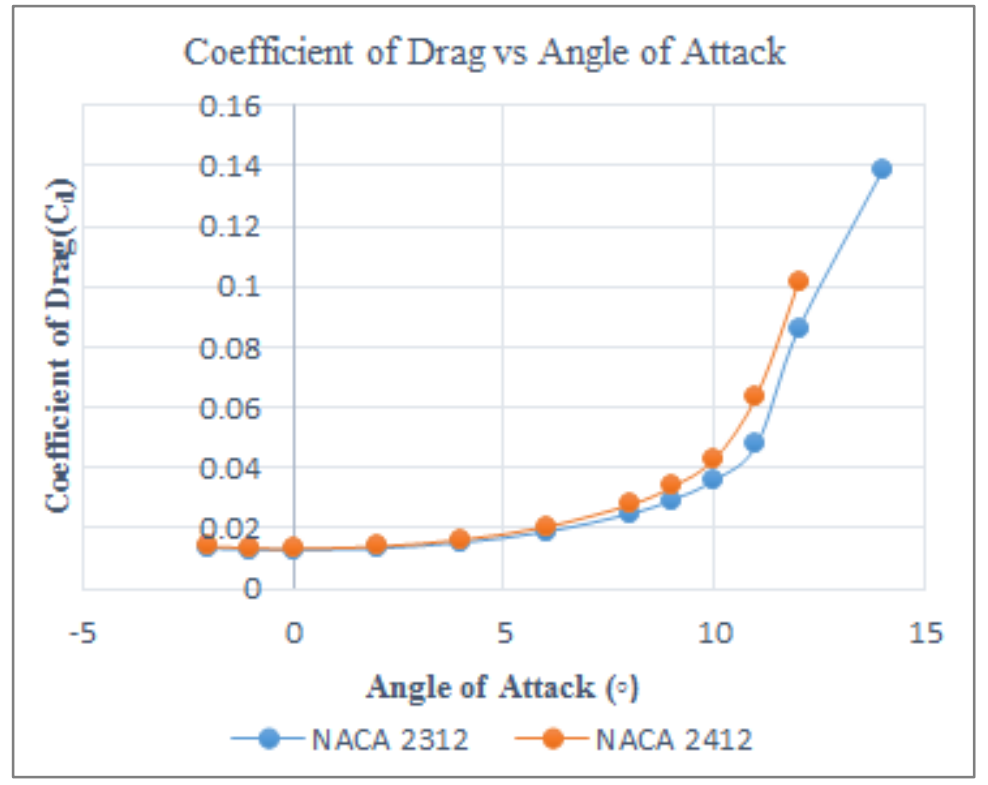

Fig 20:- Coefficient of drag vs angle of attack

The relationship between the Coefficient of Lift and the Coefficient of Drag for an aerofoil is given by drag polar equation $C_{D}=C_{D 0}+\frac{C_{L}^{2}}{\pi A e}$, where the Coefficient of Drag at zero Angle of Attack $\left(\mathrm{C}_{\mathrm{D} 0}\right)$ for an aerofoil can be known from its Cd vs $\alpha$ curve. For NACA 2312 and NACA 2412 aerofoils $\mathrm{C}_{\mathrm{DO}}$ is pointed in Fig 20.

\section{CONCLUSION}

From Fig 11 and Fig 12 it can be observed that the pressure generated on the lower surface of NACA 2312 aerofoil is greater than that on the lower surface of NACA 2412 aerofoil for an angle of attack of $8^{\circ}$. thus the lift generated on NACA 2312 is more as there is greater pressure difference on the upper and lower surface.

$>$ From Fig 14, Fig 16 and Fig 18 we can conclude that with the increase in angle of attack, the flow separation increases.

$>$ From Fig 8, Fig 10, Fig 12 we can conclude that the pressure difference between lower surface and upper surface of the aerofoil (and therefore the lift generated on aerofoil) increases with the angle of attack, becomes maximum just before the stall angle (critical condition) and then decreases with the increase in angle of attack. This can also be confirmed from Fig $19 \mathrm{Cl}$ vs $\alpha$ curve.

From Fig 19 it found that the stall angle for NACA 2412 aerofoil is $10^{\circ}$ and that for NACA 2312 aerofoil is close to $11^{\circ}$. Thus, we can conclude that NACA 2412 will stall before NACA 2312 but still the difference between their stall angles is small as already expected.

\section{REFERENCES}

[1]. John. D Anderson, Fundamentals of Aerodynamics, Fifth Edition, McGraw Hill Education (India) Private Limited.

[2]. John. D Anderson, Aircraft Performance and Design, 2010 Edition, Tata McGraw Hill Education Private Limited.

[3]. www.airfoiltools.com

[4]. Wilcox, D. C. (2008). "Formulation of the k-omega Turbulence Model Revisited". AIAA Journal. 